
\title{
25 Research Soure \\ The Effects of Birth Spacing After Cesarean Delivery on Pregnancy Outcomes: A Retrospective Cohort Study
}

\section{Qin Xu}

West China Second University Hospital of Sichuan University

Lei Ye

West China Hospital of Sichuan University

Qilin Wang

West China Second University Hospital of Sichuan University

Wei Xia

West China Second University Hospital of Sichuan University

Xiaohong Wei

West China Second University Hospital of Sichuan University

Rong Zhou ( $\nabla$ zhourong_hx@scu.edu.cn )

West China Second University Hospital of Sichuan University

\section{Research Article}

Keywords: family planning policy, Two-Child Policy, gestational diabetes mellitus (GDM), cesarean section (CS)

Posted Date: February 1st, 2021

DOl: https://doi.org/10.21203/rs.3.rs-154774/v1

License: (c) (1) This work is licensed under a Creative Commons Attribution 4.0 International License. Read Full License 


\section{Abstract}

The changing family planning policy from One-Child to Two-Child Policy, led to a significant increase in the proportion of pregnancies with variant interpregnancy intervals (IPIs) after previous cesarean section (CS). To examine the relationship between IPI and perinatal outcomes, we conducted a retrospective cohort study of 1854 women having a history of CS and delivered in 2016 at West China Second University Hospital. With an IPI of 24-59 months as the reference, the associations between various IPIs $(<24,60-119$, and $\geq 120$ months) and pregnancy outcomes were examined by multivariate logistic regression analysis with multiple models. We found that IPI $<24$ months significantly increased the risk of anemia in late pregnancy (aOR $2.09,95 \% \mathrm{Cl} 1.21-2.62, \mathrm{p}=0.008)$. $\mid \mathrm{PI}<24$ months was associated with a higher risk for incomplete uterine rupture (OR 1.30, 95\% $\mathrm{Cl} 1.05-1.61), \mathrm{IPI} \geq 60$ months was related to a lower risk for incomplete uterine rupture (IPI = 60-119 months: OR 0.77, 95\% $\mathrm{Cl} 0.62-0.95 ; \mathrm{IPI} \geq 120$ months, OR 0.59, 95\% Cl 0.38-1.08), and women with IPI $\geq 120$ months were more likely to develop gestational hypertension (GHP) $(p=0.036)$ and gestational diabetes mellitus (GDM) $(p=0.001)$. These effects became nonsignificant after adjusting possible confounders. This study revealed that IPI may combine with other factors to affect GHP, GDM, and uterine rupture in the subsequent pregnancy after previous CS.

\section{Introduction}

According to the recommendations of the World Health Organization (WHO), the interval from previous live birth and subsequent conception should be a minimum of 2 years, regardless of the previous delivery mode $^{1}$. In 2016, when the universal one-child policy was replaced with the two-child policy, all couples in China were allowed to have a second child ${ }^{2}$. Because the one-child policy had been in place for 36 years in China, this change was very likely to increase the number of high-risk parturients with typical risk factors such as advanced maternal age (AMA) and a long interpregnancy interval (IPI). Additionally, there has also been a sharp increase in pregnancies with previous cesarean section (CS) due to the high CS rates over recent decades in China ${ }^{3,4}$. Consequently, it is a great challenge for obstetricians in China to manage the growing number of high-risk parturients with multiple risk factors, such as AMA, a long IPI, and previous CS, which have been demonstrated to increase the risk of adverse pregnancy outcomes, such as uterine rupture ${ }^{5,6}$, gestational hypertension $(\mathrm{GHP})^{7,8}$, gestational diabetes mellitus $(\mathrm{GDM})^{9}$, preterm delivery, low birth weight (LBW) and neonatal intensive care unit (NICU) admission ${ }^{10-15}$.

We performed a preliminary systematic review of the association between IPI and adverse pregnancy outcomes after previous CS and found that pregnancy spacing after previous CS was related to the risk of uterine rupture, the probability of a successful vaginal birth after CS (VBAC), and the risk of placenta previa ${ }^{16}$. However, we cannot conclude the optimal IPI after previous CS because different measurements and categorizations of birth spacing were used in previous studies. Furthermore, 36 years after implementing the one-child policy, China implemented the two-child policy broadly; as a result, the number of pregnant women with long IPIs increased significantly, and this family planning policy caused 
the number of pregnancies and deliveries among Chinese women to be quite different from those of other countries. Thus, there is no relevant research conducted exclusively for Chinese women. Therefore, we conducted this large retrospective cohort study to explore the association between IPI after previous CS and adverse pregnancy outcomes.

\section{Methods}

This retrospective cohort study was conducted at West China Second University Hospital (Sichuan University), a tertiary care hospital. Women with a history of CS who gave birth from January 2016 to December 2016 at West China Second University Hospital were included in this cohort. This study was approved by the Research Ethics Committee, Chengdu, China (ref. number 2016-010; date of approval 2016-05-25) and written informed consent was obtained from all subjects. All experiments and methods were performed in accordance with relevant guidelines and regulations. Data were obtained from the electronic medical system and were supplemented by information from medical records. Two trained abstractors were instructed to review and abstract data from the medical chart.

Our primary analyses included all women who had at least one previous CS at 28 to $<42$ weeks of gestation and delivered at 28 to $<42$ weeks of gestation. We excluded women who met the following criteria: (1) underwent uterine surgery other than CS; (2) did not receive routine antenatal care; (3) had multiple pregnancies; and (4) had fetal malformations.

IPI was defined as the number of months between the date of last cesarean operation and the conception date of the subsequent delivery, which was estimated by the delivery date of the index pregnancy minus its gestational age at birth. The IPI was categorized into four groups: less than 24 months, 24 to 59 months, 60 to 119 months, and 120 months or greater.

Maternal outcomes included anemia in late pregnancy, GHP, GDM, an abnormal placental position, pernicious placenta, placenta accreta, placental abruption, premature rupture of membranes (PROM), uterine rupture (including incomplete and complete uterine rupture), postpartum hemorrhage (PPH), and hysterectomy. According to the WHO guidelines, anemia in late pregnancy was defined as a hemoglobin concentration less than $110 \mathrm{~g} / \mathrm{L}$ between 32 and 42 weeks of gestation ${ }^{41}$. The definitions of gestational hypertension complied with the consensus statement from the International Society of Study of Hypertension in Pregnancy (ISSHP) ${ }^{42}$. The definitions of GDM (where Grade A1 indicates that blood glucose is well controlled by nondrug therapy during pregnancy and Grade A2 indicates that blood glucose should be controlled by drugs during pregnancy) complied with the WHO criteria ${ }^{43}$. Uterine rupture was measured during CS by experienced obstetricians, and complete rupture was defined as a tear through all layers of the uterine wall, and incomplete rupture was defined as a tear in the muscular layers with intact serosa or amniotic membranes ${ }^{44}$. Adverse fetal outcomes included preterm birth, admission to the NICU, low 1-min Apgar score, and LBW. LBW was defined as a birth weight less than $2500 \mathrm{~g}$, and a low 1-min Apgar score was defined as an Apgar score of less than 10 during 1 minute after birth evaluated by a professional obstetrician. 
The demographic and clinical characteristics of the four groups may be significantly different, and these factors may be potential confounding factors affecting the association between IPI and perinatal outcomes. We established multivariable logistic regression analysis models to adjust for these factors and then analyzed the effect of the IPI after CS on adverse maternal and fetal outcomes. Since previous studies have confirmed that emergency CS significantly increases the risk of adverse perinatal outcomes ${ }^{45}$, we established analysis models to separately analyze the relationships between IPI after emergency CS or elective CS and pregnancy outcomes by using a multivariable logistic regression method.

Sociodemographic characteristics and adverse pregnancy outcomes were compared among the four groups, the chi-squared test was used for categorical variables, and one-way analysis of variance was used for continuous variables. Multivariable logistic regression analysis was separately conducted for the association between different IPIs and each pregnancy outcome after controlling for the known and suspected confounding factors, and the analysis used an IPI of 24-59 months as the reference category, as it was the recommended IPI by WHO guidelines ${ }^{1}$. Data analyses were performed using the software package SPSS statistics version 21.0 (SPSS Inc.) A p-value $<0.05$ for both sides was considered significant.

The datasets generated during and/or analyzed during the current study are available from the corresponding author on reasonable request.

\section{Results}

A total of 1854 deliveries with a history of CS were reported at West China Second University Hospital (Sichuan University) between January 1, 2016, and December 31, 2016. According to the exclusion criteria, 192 women were excluded: 51 cases without routine antenatal care, 85 cases of multiple pregnancy, 44 cases of fetal malformation, and 12 cases of uterine surgery other than CS. The final sample size for this retrospective cohort study was 1662, and these women were categorized into 4 groups according to different IPIs: 121 women with an IPI of < 24 months, 583 women with an IPI of 24 to 59 months, 712 women with an IPI of 60 to 119 months, and 246 women with an IPI of 120 months or greater (Figure 1).

Maternal characteristics. In the entire cohort, the mean maternal age was 33.3 years (SD 2.9), and women with an IPI of 120 months or greater were significantly older than the other three groups, with a value of 37.1 years (SD 3.0). To test the collinearity of the interpregnancy interval and maternal age, we performed a collinearity diagnostic, which indicated low collinearity between the two factors. Women with an IPI of 120 months or greater had a higher prevalence of gravidity $\geq 3$ than the other four groups while having a lower prevalence of parity $\geq 2$ and prior $C S \geq 2$ and a smaller gestational age at delivery. In addition, significant differences were found among the four groups in terms of the distributions of maternal body mass index (BMI) $(p=0.005)$ and educational status $(p<0.001)$. Women with an IPI of less than 24 months had a history of 2 CSs or more, and among them, the proportion (3.5\%) of in vitro fertilization and 
embryo transfer (IVF-ET) was higher than the rates among the other three groups. There were no significant differences in the distribution of history of vaginal delivery or in the proportion of pregnant women with chronic hypertension or pregestational diabetes mellitus (PGDM) among the four groups. Only $2.8 \%(n=47)$ of women achieved VBAC, and the rates of emergency CS and CS with indications were not different across the four groups (Table 1).

Univariate analysis of the correlation between IPIs and pregnancy outcomes. Compared with the other three groups, women with an IPI of 120 months or greater had a higher rate of GHP $(6.1 \%, p<0.036)$ and $\operatorname{GDM}(34.9 \%, p=0.001)$. There were statistically significant differences in the incidence of uterine rupture among the four groups $(p=0.041)$, and the proportion of uterine rupture in women with an IPI of 120 months or greater $(4.9 \%, n=12)$ was significantly lower than that among women in the other three groups. No significant difference was found across the four groups regarding to maternal outcomes, including anemia, low placenta, placenta previa, pernicious placenta, placenta accreta, placental abruption, PROM, PPH, and hysterectomy. Groups with an IPI of less than 24 months $(4.1 \%, n=5)$ and an IPI of 120 months or greater $(6.1 \%, n=15)$ were more likely to deliver before 34 weeks of gestation $(p=$ 0.002). Babies in the group of women whose IPI was equal to or greater than 120 months had significantly lower birth weights $(p=0.017)$ and shorter birth lengths $(p=0.035)$ than those in the other three groups. No significant difference was found across the four groups regarding to perinatal outcomes, including low 1-min Apgar score, LBW and admission to the NICU (Table 2).

Multivariable logistic regression analysis of the associations among anemia, GHP, GDM and IPI. With an IPI of 24-59 months as the reference category, our analysis suggested that an IPI of less than 24 months was related to an increased risk of developing anemia in late pregnancy (adjusted odds ratio (aOR) 2.09, $95 \% \mathrm{Cl} 1.21-2.62, \mathrm{p}=0.008$ ), while an IPI of 60 to 119 months or 120 months or greater was not associated with anemia in the third trimester (IPI of 60 to 119 months, aOR 1.37, 95\% Cl 0.94-1.98, p = 0.098; IPI of 120 months or greater, aOR $1.39,95 \% \mathrm{Cl} 0.81-12.38, \mathrm{p}=0.232$ ). IPIs of less than 24 months, 60 to 119 months, and 120 months or greater had no significant effect on the risk of developing GHP or GDM (Table 3).

Multivariable logistic regression analysis of the associations between other pregnancy outcomes and IPIs. Multivariable logistic regression analysis using an IPI of 24-59 months as the reference category was conducted to examine the associations between different IPIs and adverse perinatal outcomes among 1662 women with previous CS. Model 1 did not adjust for any confounding factors (Table 4), while model 2 adjusted for maternal age, maternal BMI, educational status, assisted reproductive technology (ART), number of previous CSs, previous vaginal delivery and previous emergency CSs (Table 5). In model 1, an IPI of less than 24 months significantly increased the risk of incomplete uterine rupture (OR 1.30, 95\% Cl 1.05-1.61), while an IPI of 60 to 119 months (OR 0.77, 95\% $\mathrm{Cl} 0.62-0.95$ ) and 120 months or greater (OR $0.59,95 \% \mathrm{Cl} 0.38-1.08)$ significantly reduced the risk of incomplete uterine rupture. In model 2, after adjustments for some confounders, the results suggested that the IPI was not a risk factor for incomplete uterine rupture. In models 1 and 2, we found that IPI had no effect on other adverse 
perinatal outcomes, including pernicious placenta, abnormal placental position, PROM, PPH, hysterectomy, low 1-min Apgar score, and admission to the NICU.

Studies have confirmed that emergency CS can significantly increase the risk of adverse perinatal outcomes ${ }^{17}$. The other four models were established by using multivariable logistic regression analysis to analyze the relationship between the IPI of 552 women with emergency CS and that of 1099 women with elective CS and perinatal outcomes separately. Model 3 did not adjust for any confounding factors in women with emergency CS (Table 6), while model 4 adjusted for maternal age, maternal BMI, educational status, ART, number of previous CSs, and previous vaginal delivery (Table 7). In models 3 and 4, the association between IPI and incomplete uterine rupture among women with emergency CS always remained nonsignificant $(p>0.05)$. Model 5 did not adjust for any confounding factors among women with elective CS (see Supplementary Table S1), while model 6 adjusted for maternal age, maternal BMI, educational status, ART, number of previous cesarean sections, and previous vaginal delivery (see Supplementary Table S2). In model 5, IPI was a risk factor for incomplete uterine rupture $(p=0.048)$. An IPI of less than 24 months significantly increased the risk of incomplete uterine rupture (OR $1.35,95 \% \mathrm{Cl}$ 1-1.82), and an IPI of 60 to 119 months (OR $0.74,95 \% \mathrm{Cl} 0.55-1$ ) or 120 months or greater (OR $0.55,95 \%$ $\mathrm{Cl}$ 0.3-0.99) significantly reduced the risk of incomplete uterine rupture (see Supplementary Table S1). In model 6, after adjustments for some confounders, we found that the IPI of women with a history of selected CS was not a risk factor for incomplete uterine rupture $(p=0.131)$ (see Supplementary Table S2).

\section{Discussion}

Because birth spacing might affect maternal health status and nutrient concentrations, it is plausible that the IPI after CS is associated with perinatal outcomes. Some studies have recognized the increased risk of anemia in women with IPIs shorter than 6 to 24 months regardless of a history of $\mathrm{CS}^{18-20}$. A study found that a short IPI of $<18$ months after CS was related to a greater risk of anemia ${ }^{21}$. Our study indicates that an IPI of $<24$ months increased the risk of anemia in late pregnancy. Anemia among women with a short IPI is a status of total iron depletion, which is seen to be the consequence of inadequate time from previous delivery to replenish the iron stores ${ }^{22}$.

Many studies have reported the association between birth spacing and adverse neonatal outcomes ${ }^{15}$, while limited studies have been conducted exclusively for women with a history of a previous CS. A large meta-analysis of multiparous women in 2006 concluded that IPIs of $<18$ months and of $\geq 60$ months had the highest risk for preterm birth ${ }^{15}$. Moreover, Class et al used cousin and sibling comparisons and revealed that an IPI of 60 months or greater had elevated risks for preterm delivery ( $<37$ weeks) ${ }^{23}$. Compared with an IPI of 24-59 months, our results implied that the rate of premature delivery before 34 weeks increased in the group of women with an IPI of $<24$ months and of $\geq 120$ months. Due to the substantial growth of parturients with extremely long IPIs after implementation of the revised reproductive policy in China, we separately analyzed the association between adverse perinatal outcomes 
and IPIs of $\geq 120$ months, which was not addressed in the non-Chinese studies. Zhu et al attributed the relationship between long intervals and adverse perinatal outcomes to "physiological regression", the hypothesis being that women's reproductive capacity after delivery physiologically declines and gradually reaches the levels of primigravid women ${ }^{24}$. The reason for the lack of an association between a short IPI after previous CS and adverse perinatal outcomes could be the small proportion (7.28\%) of short IPIs in this study.

The relationship between IPI after CS and abnormal placental position was reported in two studies, which reported that both were unrelated ${ }^{25,26}$. Our investigation also indicated no association between abnormal placental position and IPI. The association between a short IPI and an increased risk of inadequate healing of uterine scars has been recognized ${ }^{27}$. Although our analysis included maternal age as a potential confounder, we still attribute the association between a long IPI and abnormal placental position to the physiological changes in the uterus in AMA. Several studies have observed an increased occurrence of placenta previa among women with AMA and thought that AMA may lead to compromised uteroplacental blood flow, thus increasing the risk of placental previa ${ }^{28-30}$. We found that since only 9 patients were pregnant within 1 year after $C S$ and none of them had abnormal placental positions, there may be a bias.

Our investigation demonstrated that the incidence of GHP and GDM was significantly increased among women with IPIs of $\geq 120$ months. Nevertheless, the effect was nonsignificant after adjustment. Hanley et al showed that women with a longer IPI were more likely to develop GDM or GHP31, but the study took women with multiple pregnancies as its own control, and maternal age increased with increasing in IPI. In our study, women with an IPI of $\geq 120$ months were significantly older than those in the other three groups, and nearly $80 \%$ of these women had a gestational age of over 35 weeks. In addition, overweight and obesity have also been proven to be risk factors for GHP and GDM ${ }^{18,19}$. However, in our study, there were no significant differences in the proportions of high maternal BMI among the four groups. Therefore, the correlation between GHP, GDM and IPI may be affected by maternal aging.

Repeat CS is acknowledged to increase the risk of maternal complications ${ }^{32}$, and TOLAC is an option for women with a scarred uterus. Successful TOLAC can avoid numerous surgery-related morbidities and is beneficial to subsequent pregnancies. However, failed TOLAC is related to an increased risk of uterine rupture, which is detrimental for both the parturient and the fetus ${ }^{33,34}$. A systematic study reported that the median incidence of complete uterine rupture was $1 \%$ among women with previous $\mathrm{CS}^{35}$, but the range of incidences of incomplete uterine rupture was wide at $2.1 \%-10.1 \% 36,37$. In this study, $8.7 \%(n=$ 145) of women were found to have incomplete uterine rupture during the operation, while no complete uterine rupture was reported. Previous studies indicated that the risk of complete uterine rupture increased with AMA, grandmultiparity $(\geq 6)$, an extremely short IPI and macrosomia ${ }^{6,38-40}$. We found that the IPI of women with a history of emergency CS was not related to the occurrence of uterine rupture, while in the group of women with a history of selected CS, the risk of incomplete uterine rupture decreased in the groups with IPIs of 60-119 months and $\geq 120$ months. Studies have reported a 
significantly increased risk of uterine rupture during emergency CS, but mothers with elective repeat cesarean section (ERCD) had almost no risk of uterine rupture $(0-0.004 \%)^{39}$. We assumed that the risk of uterine rupture was underestimated for elective CS, mitigating the risk of uterine rupture.

One of the strengths of this study is its focus on the effects of extremely long IPIs, which is in accordance with the current birth policy in China. Our results suggest that shorter and longer IPIs should be a risk factor in subsequent pregnancy for women with a history of CS. In addition, our analysis of the adverse pregnancy outcomes related to IPI is relatively systemic, comprising scar-related morbidities and common pregnancy morbidities. The main limitation of our study is its retrospective design, which precludes a power analysis. Moreover, the rate of trial of labor after cesarean (TOLAC) was only $2.87 \%$ ( $n$ $=47$ ), and the incidence of uterine rupture may be underestimated. We could not accurately analyze the effects of IPI on the success of VBAC or the risk of uterine rupture for the small proportion of women with TOLAC. A larger, prospective study would have to be carried out to identify candidates for TOLAC and provide intensive prenatal care to guarantee safety during TOLAC. Our previous systematic evaluation found that an IPI of more than 6-8 months after CS can reduce the risk of adverse maternal and neonatal outcomes, which is quite different from the results of this study. Our conclusions regarding a short IPI are based on a small sample size and should thus be interpreted with caution. Given that the WHO recommends an IPI of $\geq 24$ months, further studies of a short IPI would have to be in a prospective design.

\section{Conclusion}

Our study indicates that an IPI of $<24$ months is related to a greater risk of anemia in late pregnancy. IPI may synergize with other factors to increase the risk of incomplete uterine rupture. An extremely long IPI of $\geq 120$ months is related to higher risks of GHP and GDM due to increasing maternal age. An optimal IPI and gestational age should be considered for families planning to have a second baby.

\section{Declarations}

\section{Acknowledgments}

All the analyses, interpretations and conclusions that were derived from the data source and included in this article are those of the authors. This study was supported by West China Second University Hospital (Sichuan University).

\section{Contribution to authorship}

R. Z. was involved in the conception and planning of the study, interpretation of the data, and critical revision of the article; Q. X. was involved in carrying out of the study, writing the first draft and critical revision of the article; $L$. Y. was involved in the interpretation of the data, and co-writing of the article; $Q$. W. and W. X. was involved in acquisition, analysis of the data; X. W. was involved in analysis of the data and revision of the article. 


\section{Disclosure of interests}

None of the authors has a conflict of interest.

\section{Details of ethics approval}

Ethical approval was obtained from the Research Ethics Committee, Chengdu, China (ref. number 2016010; date of approval 2016-05-25).

\section{Funding}

This work was supported by the National Natural Science Foundation of China (No. 81571465).

\section{References}

1. Marston C. Report of a WHO Technical Consultation on Birth Spacing. Geneva, Switzerland. 50, 137 (2006).

2. Xie, M. et al. Risk for cesarean section in women of advanced maternal age under the changed reproductive policy in China: a cohort study in a tertiary hospital in southwestern China. J Obstet Gynaecol Res. 45, 1866-1875 (2019).

3. Vogel, J. P. et al. Use of the Robson classification to assess cesarean section trends in 21 countries: a secondary analysis of two WHO multicountry surveys. Lancet Glob Health. 3, e260-270 (2015).

4. Li, H. T. et al. Geographic Variations and Temporal Trends in Cesarean Delivery Rates in China, 20082014. 317, 69-76 (2017).

5. Shipp, T. D. et al. The association of maternal age and symptomatic uterine rupture during a trial of labor after prior cesarean delivery. Obstet Gynecol. 99, 585-588 (2002).

6. Hochler, H. et al. Grandmultiparity, maternal age, and the risk for uterine rupture-A multicenter cohort study. Acta Obstet Gynecol Scand. 99, 267-273 (2020).

7. Timofeev, J. et al. Obstetric complications, neonatal morbidity, and indications for cesarean delivery by maternal age. Obstet Gynecol. 122, 1184-1195 (2013).

8. Dietl, A. \& Farthmann, J. Gestational hypertension and advanced maternal age. Lancet (London, England). 386, 1627-1628 (2015).

9. Taddei, S., Virdis, A., Ghiadoni, L., Versari, D. \& Salvetti, A. Endothelium, aging, and hypertension. Current hypertension reports. 8, 84-89 (2006).

10. Hsieh, T. T. et al. Advanced maternal age and adverse perinatal outcomes in an Asian population. Eur J Obstet Gynecol Reprod Biol. 148, 21-26 (2010).

11. Getahun, D., Oyelese, Y., Salihu, H. M. \& Ananth, C. V. Previous cesarean delivery and risks of placenta previa and placental abruption. Obstet Gynecol. 107, 771-778 (2006).

12. Chen, I., Jhangri, G. S. \& Chandra, S. Relationship between interpregnancy interval and congenital anomalies. American journal of obstetrics and gynecology. 210, 564.e561-568 (2014). 
13. King, J. C. The risk of maternal nutritional depletion and poor outcomes increases in early or closely spaced pregnancies. The Journal of nutrition. 133, 1732s-1736s (2003).

14. Fuentes-Afflick, E. \& Hessol, N. A. Interpregnancy interval and the risk of premature infants. Obstet Gynecol. 95, 383-390 (2000).

15. Conde-Agudelo, A., Rosas-Bermúdez, A. \& Kafury-Goeta, A. C. Birth spacing and risk of adverse perinatal outcomes: a meta-analysis. 295, 1809-1823 (2006).

16. Ye, L., Cao, W., Yao, J., Peng, G. \& Zhou, R. Systematic review of the effects of birth spacing after cesarean delivery on maternal and perinatal outcomes. Int J Gynaecol Obstet. 147, 19-28 (2019).

17. Ananth, C. V., Oyelese, Y., Yeo, L., Pradhan, A. \& Vintzileos, A. M. Placental abruption in the United States, 1979 through 2001: temporal trends and potential determinants. American journal of obstetrics and gynecology. 192, 191-198 (2005).

18. Singh, K., Fong, Y. F. \& Arulkumaran, S. Anaemia in pregnancy-a cross-sectional study in Singapore. European journal of clinical nutrition. 52, 65-70 (1998).

19. Dairo, M. D. \& Lawoyin, T. O. Socio-demographic determinants of anaemia in pregnancy at primary care level: a study in urban and rural Oyo State, Nigeria. African journal of medicine and medical sciences. 33, 213-217 (2004).

20. Conde-Agudelo, A., Rosas-Bermúdez, A. \& Kafury-Goeta, A. C. Effects of birth spacing on maternal health: a systematic review. American journal of obstetrics and gynecology. 196, 297-308 (2007).

21. Lilungulu, A., Matovelo, D., Kihunrwa, A. \& Gumodoka, B. Spectrum of maternal and perinatal outcomes among parturient women with preceding short inter-pregnancy interval at Bugando Medical Centre, Tanzania. Matern Health Neonatol Perinatol. 1, 1 (2015).

22. Conde-Agudelo, A. \& Belizán, J. M. Maternal morbidity and mortality associated with interpregnancy interval: cross sectional study. BMJ (Clinical research ed.). 321, 1255-1259 (2000).

23. Class, Q. A. et al. Within-Family Analysis of Interpregnancy Interval and Adverse Birth Outcomes. Obstet Gynecol. 130, 1304-1311 (2017).

24. Zhu, B. P., Rolfs, R. T., Nangle, B. E. \& Horan, J. M. Effect of the interval between pregnancies on perinatal outcomes. N Engl J Med. 340, 589-594 (1999).

25. Bujold, E., Mehta, S. H., Bujold, C. \& Gauthier, R. J. Interdelivery interval and uterine rupture. American journal of obstetrics and gynecology. 187, 1199-1202 (2002).

26. Birara, M. \& Gebrehiwot, Y. Factors associated with success of vaginal birth after one caesarean section (VBAC) at three teaching hospitals in Addis Ababa, Ethiopia: a case control study. BMC pregnancy and childbirth. 13, 31 (2013).

27. Al-Zirqi, I., Daltveit, A. K., Forsén, L., Stray-Pedersen, B. \& Vangen, S. Risk factors for complete uterine rupture. American journal of obstetrics and gynecology. 216, 165.e161-165.e168 (2017).

28. Faiz, A. S. \& Ananth, C. V. Etiology and risk factors for placenta previa: an overview and metaanalysis of observational studies. The journal of maternal-fetal \& neonatal medicine : the official 
journal of the European Association of Perinatal Medicine, the Federation of Asia and Oceania Perinatal Societies, the International Society of Perinatal Obstet. 13, 175-190 (2003).

29. Ogawa, K. et al. Association between very advanced maternal age and adverse pregnancy outcomes: a cross sectional Japanese study. BMC pregnancy and childbirth. 17, 349 (2017).

30. Wennberg, A. L. et al. Effect of maternal age on maternal and neonatal outcomes after assisted reproductive technology. Fertility and sterility. 106, 1142-1149.e1114 (2016).

31. Hanley, G. E., Hutcheon, J. A., Kinniburgh, B. A. \& Lee, L. Interpregnancy Interval and Adverse Pregnancy Outcomes: An Analysis of Successive Pregnancies. Obstet Gynecol. 129, 408-415 (2017).

32. Gurol-Urganci, I. et al. Impact of Caesarean section on subsequent fertility: a systematic review and meta-analysis. Human reproduction (Oxford, England). 28, 1943-1952 (2013).

33. Fox, N. S. et al. Pregnancy outcomes in patients with prior uterine rupture or dehiscence. Obstet Gynecol. 123, 785-789 (2014).

34. Fitzpatrick, K. E., Kurinczuk, J. J., Bhattacharya, S. \& Quigley, M. A. Planned mode of delivery after previous cesarean section and short-term maternal and perinatal outcomes: A population-based record linkage cohort study in Scotland. PLoS medicine. 16, e1002913 (2019).

35. Hofmeyr, G. J., Say, L. \& Gülmezoglu, A. M. WHO systematic review of maternal mortality and morbidity: the prevalence of uterine rupture. 112, 1221-1228 (2005).

36. Nielsen, T. F., Ljungblad, U. \& Hagberg, H. Rupture and dehiscence of cesarean section scar during pregnancy and delivery. American journal of obstetrics and gynecology. 160, 569-573 (1989).

37. Fogelberg, M., Baranov, A., Herbst, A. \& Vikhareva, O. Underreporting of complete uterine rupture and uterine dehiscence in women with previous cesarean section. The journal of maternal-fetal \& neonatal medicine: the official journal of the European Association of Perinatal Medicine, the Federation of Asia and Oceania Perinatal Societies, the International Society of Perinatal Obstet. 30, 2058-2061 (2017).

38. Jastrow, N. et al. Effect of birth weight on adverse obstetric outcomes in vaginal birth after cesarean delivery. Obstet Gynecol. 115, 338-343 (2010).

39. Alcalay, M. et al. Prelabour rupture of membranes at term: early induction of labour versus expectant management. Eur J Obstet Gynecol Reprod Biol. 70, 129-133 (1996).

40. Bérubé, L. et al. Factors associated with lower uterine segment thickness near term in women with previous caesarean section. J Obstet Gynaecol Can. 33, 581-587 (2011).

41. Breymann, C., Honegger, C., Hösli, I. \& Surbek, D. Diagnosis and treatment of iron-deficiency anaemia in pregnancy and postpartum. Archives of gynecology and obstetrics. 296, 1229-1234 (2017).

42. Tranquilli, A. L. et al. The classification, diagnosis and management of the hypertensive disorders of pregnancy: a revised statement from the ISSHP. Pregnancy Hypertens. 4, 97-104 (2014).

43. Diagnosis and classification of diabetes mellitus. Diabetes care. 36 Suppl 1, S67-74 (2013).

44. Al-Zirqi, I., Stray-Pedersen, B., Forsén, L., Daltveit, A. K. \& Vangen, S. Validation study of uterine rupture registration in the Medical Birth Registry of Norway. Acta obstetricia et gynecologica 
Scandinavica. 92, 1086-1093 (2013).

45. Lydon-Rochelle, M., Holt, V. L., Easterling, T. R. \& Martin, D. P. Risk of uterine rupture during labor among women with a prior cesarean delivery. N Engl J Med. 345, 3-8 (2001).

\section{Tables}

Table 1. Baseline Maternal Characteristics in the Four Groups Categorized by Interpregnancy Interval. 


\begin{tabular}{|c|c|c|c|c|c|}
\hline \multirow[t]{2}{*}{ Maternal Parameters } & IPI of & IPI of & IPI of & & \multirow{2}{*}{$\begin{array}{l}P \\
\text { value }\end{array}$} \\
\hline & $\begin{array}{l}<24 \text { mon } \\
(n=121)\end{array}$ & $\begin{array}{l}24-59 \text { mon } \\
(n=583)\end{array}$ & $\begin{array}{l}60-119 \\
\text { mon } \\
(n=712)\end{array}$ & $\begin{array}{l}\geq 120 \text { mon } \\
(n=246)\end{array}$ & \\
\hline $\begin{array}{l}\text { Maternal age at index conception } \\
\text { (y) }\end{array}$ & $30.75 \pm 3.5$ & $31.43 \pm 3.31$ & $33.88 \pm 3.2$ & $37.14 \pm 2.95$ & $\dot{<} 0.001$ \\
\hline$\geq 35$ & $16(13.2)$ & $86(14.8)$ & $284(39.9)$ & $195(79.3)$ & 0.001 \\
\hline$<35$ & $105(86.8)$ & $497(85.2)$ & $428(60.1)$ & $51(20.7)$ & \\
\hline Education (y) & & & & & $\dot{0} 001$ \\
\hline$\leq 12$ & $9(7.4)$ & $36(6.2)$ & $52(7.4)$ & $23(9.4)$ & \\
\hline $13-16$ & $10(8.3)$ & $48(8.3)$ & $74(10.5)$ & $34(13.9)$ & \\
\hline$\geq 17$ & $102(84.3)$ & $497(85.5)$ & $578(82.1)$ & $188(76.7)$ & \\
\hline BMI, No. $\left(\mathrm{Kg} / \mathrm{m}^{2}\right)$ & & & & & 0.005 \\
\hline$<18$ & $19(15.7)$ & $74(12.7)$ & $55(7.7)$ & $14(5.7)$ & \\
\hline $18-23.9$ & $80(66.1)$ & $395(67.8)$ & $525(73.7)$ & $173(70.3)$ & \\
\hline $24-27.9$ & $22(14.9)$ & $93(16)$ & $116(16.3)$ & $51(20.7)$ & \\
\hline$>28$ & $4(3.3)$ & $21(3.6)$ & $16(2.2)$ & $8(3.3)$ & \\
\hline Number of previous pregnancies & & & & & $<.001$ \\
\hline$\geq 3$ & $66(54.5)$ & $366(62.8)$ & $530(74.4)$ & $218(88.6)$ & \\
\hline$<3$ & $55(45.5)$ & 217 (37.2) & $182(25.6)$ & $28(11.4)$ & \\
\hline Parity $\geq 2$ & $16(13.2)$ & $38(6.5)$ & $26(3.7)$ & $10(4.1)$ & $\dot{0} 001$ \\
\hline Prior cesareans $\geq 2$ & $16(13.2)$ & $33(5.7)$ & $21(2.9)$ & $5(2.0)$ & 0.001 \\
\hline Prior vaginal birth & $4(3.3)$ & $8(1.4)$ & $11(1.5)$ & $6(2.4)$ & 0.384 \\
\hline IVF-ET & $2(3.5)$ & $6(1.0)$ & $4(0.6)$ & $3(1.2)$ & 0.007 \\
\hline Preexisting hypertension & $2(1.7)$ & $2(0.3)$ & $4(0.6)$ & $4(1.6)$ & 0.128 \\
\hline Preexisting diabetes & $0(0)$ & $3(0.5)$ & $2(0.3)$ & $2(0.8)$ & 0.60 \\
\hline $\begin{array}{l}\text { Gestational age at delivery } \\
\text { (weeks) }\end{array}$ & $38.05 \pm 1.75$ & $\begin{array}{l}38.07 \pm \\
1.81\end{array}$ & $\begin{array}{l}38.12 \pm \\
1.76\end{array}$ & $\begin{array}{l}37.72 \pm \\
2.21\end{array}$ & 0.027 \\
\hline
\end{tabular}




\begin{tabular}{|llllll|}
\hline Mode of delivery & \multicolumn{4}{l|}{0.178} & \\
\hline Repeated cesarean section & $117(96.7)$ & $560(96.1)$ & $696(97.8)$ & $242(98.4)$ & \\
\hline Vaginal birth after CS & $4(3.3)$ & $23(3.9)$ & $16(2.2)$ & $4(1.6)$ & \\
\hline Type of repeated cesarean section & & & & & \\
\hline Emergency cesarean section & $38(32.2)$ & $179(31.9)$ & $220(31.6)$ & $87(36.0)$ & 0.641 \\
\hline CS with indications & $45(37.2)$ & $191(34)$ & $216(31)$ & $85(35.1)$ & 0.403 \\
\hline
\end{tabular}

Data are expressed as mean $\pm S D$, or $n(\%)$ with $p$-value from exact chi-square.

IPI, interpregnancy interval.

BMI, body mass index; IVF-ET, in vitro fertilization and embryo transfer.

Table 2. Rates of Maternal and Neonatal outcomes in the Four Groups Categorized by Interpregnancy Interval. 


\begin{tabular}{|c|c|c|c|c|c|}
\hline \multirow[t]{2}{*}{ Perinatal outcome } & IPI of & IPI of & IPI of & & \multirow{2}{*}{$\begin{array}{l}P \\
\text { value }\end{array}$} \\
\hline & $\begin{array}{l}<24 \text { mon } \\
(n=121)\end{array}$ & $\begin{array}{l}24-59 \text { mon } \\
(n=583)\end{array}$ & $\begin{array}{l}60-119 \\
\text { mon } \\
(n=712)\end{array}$ & $\begin{array}{l}\geq 120 \text { mon } \\
(n=246)\end{array}$ & \\
\hline Anemia & $22(18.2)$ & $57(9.8)$ & $90(12.6)$ & $32(13)$ & 0.057 \\
\hline GHP & $15(4.2)$ & $5(2.6)$ & $22(3.1)$ & $15(6.1)$ & 0.036 \\
\hline GDM & $21(18.2)$ & $120(20.6)$ & $156(21.9)$ & $86(34.9)$ & 0.001 \\
\hline Grade A1 & $17(14.9)$ & $107(18.4)$ & $136(19.1)$ & $79(32.1)$ & \\
\hline Grade A2 & $4(3.3)$ & $13(2.2)$ & $20(2.8)$ & $7(2.8)$ & \\
\hline Placenta inherence & $5(8.9)$ & $46(7.9)$ & $50(7.0)$ & $21(8.5)$ & 0.9 \\
\hline Placental position & & & & & 0.256 \\
\hline Normal & $107(88.4)$ & $522(89.5)$ & $637(89.5)$ & $215(87.4)$ & \\
\hline Low placenta & $9(7.4)$ & $18(3.1)$ & $31(4.4)$ & $16(6.5)$ & \\
\hline $\begin{array}{l}\text { Partial or marginal placenta } \\
\text { previa }\end{array}$ & $1(0.8)$ & $10(1.7)$ & $16(2.2)$ & $4(1.6)$ & \\
\hline Complete placenta previa & $4(3.3)$ & $33(5.7)$ & $28(3.9)$ & $11(4.5)$ & \\
\hline Pernicious placenta & $7(5.8)$ & $40(6.9)$ & $40(5.6)$ & $19(7.7)$ & 0.629 \\
\hline Placenta accreta & $11(9.1)$ & $46(7.9)$ & $50(7.0)$ & $21(8.5)$ & 0.787 \\
\hline PROM & $17(14)$ & $68(11.7)$ & $108(15.2)$ & $29(11.8)$ & 0.258 \\
\hline Uterine rupture & $12(9.9)$ & $63(10.8)$ & $58(8.1)$ & $12(4.9)$ & 0.041 \\
\hline Placental abruption & $2(1.7)$ & $3(0.5)$ & $2(0.3)$ & $4(1.6)$ & 0.258 \\
\hline Postpartum hemorrhage & $5(4.1)$ & $35(6.0)$ & $43(6.0)$ & $16(6.5)$ & 0.835 \\
\hline Hysterectomy & $2(1.7)$ & $6(1.0)$ & $7(1.0)$ & $3(1.2)$ & 0.921 \\
\hline Preterm birth & $16(13.2)$ & $72(12.3)$ & $77(10.8)$ & $39(15.9)$ & 0.282 \\
\hline Preterm birth $<34$ weeks & $5(4.1)$ & $15(2.6)$ & $11(1.5)$ & $15(6.1)$ & 0.002 \\
\hline Birth weight (g) & $3247 \pm 499$ & $3233 \pm 522$ & $3290 \pm 502$ & $3174 \pm 558$ & 0.017 \\
\hline Birth length $(\mathrm{cm})$ & $49.25 \pm 2.39$ & $48.99 \pm 2.89$ & $49.23 \pm 2.52$ & $48.68 \pm 2.89$ & 0.035 \\
\hline LBW & $3(5.5)$ & $38(6.5)$ & $40(5.6)$ & $26(10.6)$ & 0.071 \\
\hline 1-min Apgar score $<10$ & $5(4.1)$ & $3(5.3)$ & $28(3.9)$ & $13(5.3)$ & 0.625 \\
\hline NICU admission & $17(12.7)$ & $57(9.8)$ & $72(10.1)$ & $28(11.4)$ & 0.519 \\
\hline
\end{tabular}


Data are expressed as mean $\pm \mathrm{SD}$, or $\mathrm{n}(\%)$ with $\mathrm{p}$-value from exact chi-square.

IPI, interpregnancy interval.

GDM, gestational diabetes mellitus; GHP, gestational hypertension; PROM, premature rupture of membrane.

LBW, the birth weight of newborns is less than 2500g; NICU, neonatal intensive care.

Table 3. Association among Anemia, GHP, GDM and IPI in the Three Groups with IPI of $<24,60-119$ and $\geq$ 120 months.

\begin{tabular}{|c|c|c|c|c|c|c|}
\hline & \multicolumn{2}{|c|}{ IPI of $<24 \operatorname{mon}(n=121)$} & \multicolumn{2}{|c|}{ IPI of $60-119$ mon $(n=712)$} & \multicolumn{2}{|c|}{ IPI of $\geq 120$ mon $(n=246)$} \\
\hline & aOR (95\% Cl) & $P$ value & aOR (95\% Cl) & $P$ value & aOR $(95 \% \mathrm{Cl})$ & $P$ value \\
\hline Anemia & $2.09(1.21-3.62)$ & 0.008 & $1.37(0.94-1.98)$ & 0.098 & $1.39(0.81-2.38)$ & 0.232 \\
\hline GHP & $1.91(0.67-5.45)$ & 0.227 & $1.06(0.53-2.13)$ & 0.874 & $1.65(0.69-3.98)$ & 0.262 \\
\hline GDM & $1.28(0.73-2.23)$ & 0.395 & $1.21(0.89-1.64)$ & 0.218 & $0.86(0.58-1.3)$ & 0.482 \\
\hline
\end{tabular}

IPI, interpregnancy interval.

aOR, adjusted odds ratio; $\mathrm{Cl}$, confidential index; GHP, gestational hypertension; GDM, gestational diabetes mellitus.

Adjusted for maternal age, maternal body mass index, education status, gravidity, number of previous cesarean section.

Table 4. Association between other Perinatal Outcomes and IPI in the Three Groups with IPI of $<24,60$ 119 and $\geq 120$ months. 


\begin{tabular}{|c|c|c|c|c|c|}
\hline & Index & $\begin{array}{l}\text { IPI of }<24 \\
\text { mon } \\
(n= \\
121)\end{array}$ & $\begin{array}{l}\text { IPI of } 60- \\
119 \text { mon } \\
(n=712)\end{array}$ & $\begin{array}{l}\text { IPI of } \geq \\
120 \text { mon } \\
(n=246)\end{array}$ & $\begin{array}{l}\mathrm{P} \\
\text { value }\end{array}$ \\
\hline & & $\begin{array}{l}\text { aOR }(95 \% \\
\mathrm{Cl})\end{array}$ & $\begin{array}{l}\mathrm{aOR}(95 \% \\
\mathrm{Cl})\end{array}$ & $\begin{array}{l}\mathrm{aOR}(95 \% \\
\mathrm{Cl})\end{array}$ & \\
\hline Abnormal placental position & 0.084 & $\begin{array}{l}0.92(0.77- \\
1.1)\end{array}$ & $\begin{array}{l}1.09(0.91- \\
1.3)\end{array}$ & $\begin{array}{l}1.18(0.82- \\
1.97)\end{array}$ & 0.366 \\
\hline $\begin{array}{l}\text { Pernicious placenta with or without } \\
\text { placenta accreta }\end{array}$ & 0.015 & $\begin{array}{l}0.98(0.79- \\
1.22)\end{array}$ & $\begin{array}{l}1.02(0.82- \\
1.26)\end{array}$ & $\begin{array}{l}1.03(0.67- \\
1.98)\end{array}$ & 0.889 \\
\hline PROM & 0.032 & $\begin{array}{l}0.97(0.82- \\
1.14)\end{array}$ & $\begin{array}{l}1.03(0.87- \\
1.22)\end{array}$ & $\begin{array}{l}1.07(0.76- \\
1.63)\end{array}$ & 0.074 \\
\hline Uterine rupture & -0.265 & $\begin{array}{l}1.30(1.05- \\
1,61)\end{array}$ & $\begin{array}{l}0.77(0.62- \\
0.95)\end{array}$ & $\begin{array}{l}0.59(0.38- \\
1.08)\end{array}$ & 0.014 \\
\hline Postpartum hemorrhage & 0.060 & $\begin{array}{l}0.94(0.72- \\
1.23)\end{array}$ & $\begin{array}{l}1.06(0.81- \\
1.39)\end{array}$ & $\begin{array}{l}1.13(0.66- \\
2.58)\end{array}$ & 0.662 \\
\hline Hysterectomy & 0.054 & $\begin{array}{l}0.95(0.74- \\
1.21)\end{array}$ & $\begin{array}{l}1.06(0.83- \\
1.35)\end{array}$ & $\begin{array}{l}1.11(0.68- \\
2.36)\end{array}$ & 0.666 \\
\hline 1-min Apgar score $<10$ & -0.252 & $\begin{array}{l}1.28(0.62- \\
2.73)\end{array}$ & $\begin{array}{l}0.78(0.37- \\
1.61)\end{array}$ & $\begin{array}{l}0.61(0.13- \\
2.9)\end{array}$ & 0.504 \\
\hline NICU admission & -0.004 & $\begin{array}{l}1.00(0.82- \\
1.23)\end{array}$ & $\begin{array}{l}1.00(0.81- \\
1.22)\end{array}$ & $\begin{array}{l}0.99(0.66- \\
1.91)\end{array}$ & 0.966 \\
\hline
\end{tabular}

IPI, interpregnancy interval.

aOR, adjusted odds ratio; $\mathrm{Cl}$, confidential index; PROM, premature rupture of membrane.

Abnormal placental position, including low placenta, partial and complete placenta previa.

Table 5. Association between other Perinatal Outcomes and IPI in the Three Groups with IPI of $<24,60$ 119 and $\geq 120$ months. 


\begin{tabular}{|c|c|c|c|c|c|}
\hline & Index & $\begin{array}{l}\text { IPI of }<24 \\
\text { mon } \\
(n= \\
121)\end{array}$ & $\begin{array}{l}\text { IPI of } 60- \\
119 \text { mon } \\
(n=712)\end{array}$ & $\begin{array}{l}\text { IPI of } \geq \\
120 \text { mon } \\
(n=246)\end{array}$ & $\begin{array}{l}P \\
\text { value }\end{array}$ \\
\hline & & $\begin{array}{l}\mathrm{aOR}(95 \% \\
\mathrm{Cl})\end{array}$ & $\begin{array}{l}\mathrm{aOR}(95 \% \\
\mathrm{Cl})\end{array}$ & $\begin{array}{l}\mathrm{aOR}(95 \% \\
\mathrm{Cl})\end{array}$ & \\
\hline Abnormal placental position & 0.139 & $\begin{array}{l}0.87(0.71- \\
1.06)\end{array}$ & $\begin{array}{l}1.15(0.94- \\
-1.4)\end{array}$ & $\begin{array}{l}1.32(0.89- \\
1.97)\end{array}$ & 0.169 \\
\hline $\begin{array}{l}\text { Pernicious placenta with or without } \\
\text { placenta accreta }\end{array}$ & 0.103 & $\begin{array}{l}0.90(0.71- \\
1.14)\end{array}$ & $\begin{array}{l}1.11(0.88- \\
1.41)\end{array}$ & $\begin{array}{l}1.23(0.77- \\
1.98)\end{array}$ & 0.395 \\
\hline PROM & 0.059 & $\begin{array}{l}0.94(0.78- \\
1.13)\end{array}$ & $\begin{array}{l}1.06(0.88- \\
1.28)\end{array}$ & $\begin{array}{l}1.13(0.78- \\
1.63)\end{array}$ & 0.527 \\
\hline Uterine rupture & -0.193 & $\begin{array}{l}1.21(0.96- \\
1.53)^{(0)}\end{array}$ & $\begin{array}{l}0.82(0.65- \\
1.04)\end{array}$ & $\begin{array}{l}0.68(0.43- \\
1.08)\end{array}$ & 0.102 \\
\hline Postpartum hemorrhage & 0.162 & $\begin{array}{l}0.85(0.62- \\
1.15)\end{array}$ & $\begin{array}{l}1.18(0.87- \\
1.53)\end{array}$ & $\begin{array}{l}1.38(0.75- \\
2.58)\end{array}$ & 0.303 \\
\hline Hysterectomy & 0.145 & $\begin{array}{l}0.87(0.65- \\
1.14)\end{array}$ & $\begin{array}{l}1.16(0.87- \\
1.53)\end{array}$ & $\begin{array}{l}1.34(0.77- \\
2.36)\end{array}$ & 0.312 \\
\hline 1-min Apgar score <10 & -0.272 & $\begin{array}{l}1.31(0.59- \\
3.08)\end{array}$ & $\begin{array}{l}0.76(0.32- \\
1.7)\end{array}$ & $\begin{array}{l}0.58(0.11- \\
2.9)\end{array}$ & 0.516 \\
\hline NICU admission & 0.102 & $\begin{array}{l}0.90(0.72- \\
1.13)\end{array}$ & $\begin{array}{l}1.11(0.89- \\
1.38)\end{array}$ & $\begin{array}{l}1.23(0.79- \\
1.91)\end{array}$ & 0.365 \\
\hline
\end{tabular}

IPI, interpregnancy interval.

aOR, adjusted odds ratio; $\mathrm{Cl}$, confidential index; PROM, premature rupture of membrane.

Abnormal placental position, including low placenta, partial and complete placenta previa.

Aadjusted for maternal age, maternal body mass index, education status, assisted reproductive technology, number of previous cesarean section, previous vaginal delivery, previous emergency cesarean section.

Table 6. Association between IPI and other Perinatal Outcomes in Women with Emergency Cesarean Section. 


\begin{tabular}{|c|c|c|c|c|c|}
\hline & Index & $\begin{array}{l}\text { IPI of }<24 \\
\text { mon } \\
(n= \\
121)\end{array}$ & $\begin{array}{l}\text { IPI of } 60- \\
119 \text { mon } \\
(n=712)\end{array}$ & $\begin{array}{l}\text { IPI of } \geq \\
120 \text { mon } \\
(n=246)\end{array}$ & $\begin{array}{l}\mathrm{P} \\
\text { value }\end{array}$ \\
\hline & & $\begin{array}{l}\mathrm{aOR}(95 \% \\
\mathrm{Cl})\end{array}$ & $\begin{array}{l}\text { aOR }(95 \% \\
\mathrm{Cl})\end{array}$ & $\begin{array}{l}\mathrm{aOR}(95 \% \\
\mathrm{Cl})\end{array}$ & \\
\hline Abnormal placental position & 0.119 & $\begin{array}{l}0.89(0.63- \\
1.24)\end{array}$ & $\begin{array}{l}1.13(0.81- \\
1.57)\end{array}$ & $\begin{array}{l}1.27(0.66- \\
2.48)\end{array}$ & 0.482 \\
\hline $\begin{array}{l}\text { Pernicious placenta with or without } \\
\text { placenta accreta }\end{array}$ & -0.036 & $\begin{array}{l}1.04(0.73- \\
1.47)\end{array}$ & $\begin{array}{l}0.96(0.68- \\
1.37)\end{array}$ & $\begin{array}{l}0.93(0.46- \\
1.88)\end{array}$ & 0.840 \\
\hline PROM & 0.028 & $\begin{array}{l}0.97(0.74- \\
1.28)\end{array}$ & $\begin{array}{l}1.03(0.78- \\
1.35)\end{array}$ & $\begin{array}{l}1.06(0.61- \\
1.83)\end{array}$ & 0.843 \\
\hline Uterine rupture & -0.249 & $\begin{array}{l}1.28(0.94- \\
1.75)\end{array}$ & $\begin{array}{l}0.78(0.57- \\
1.06)\end{array}$ & $\begin{array}{l}0.61(0.33- \\
1.12)\end{array}$ & 0.113 \\
\hline Postpartum hemorrhage & 0.215 & $\begin{array}{l}0.81(0.47- \\
1.37)\end{array}$ & $\begin{array}{l}1.24(0.73- \\
2.14)\end{array}$ & $\begin{array}{l}1.54(0.53- \\
4.57)\end{array}$ & 0.430 \\
\hline Hysterectomy & 0.265 & $\begin{array}{l}0.77(0.46- \\
1.25)\end{array}$ & $\begin{array}{l}1.30(0.8- \\
2.16)\end{array}$ & $\begin{array}{l}1.70(0.64- \\
4.66)\end{array}$ & 0.293 \\
\hline 1-min Apgar score $<10$ & -0.503 & $\begin{array}{l}1.65(0.5- \\
6.42)\end{array}$ & $\begin{array}{l}0.61(0.16- \\
2.01)\end{array}$ & $\begin{array}{l}0.37(0.02- \\
4.05)\end{array}$ & 0.428 \\
\hline NICU admission & 0.035 & $\begin{array}{l}0.97(0.69- \\
1.35)\end{array}$ & $\begin{array}{l}1.04(0.74- \\
1.46)\end{array}$ & $\begin{array}{l}1.07(0.55- \\
2.12)\end{array}$ & 0.838 \\
\hline
\end{tabular}

IPI, interpregnancy interval.

aOR, adjusted odds ratio; $\mathrm{Cl}$, confidential index; PROM, premature rupture of membrane.

Abnormal placental position, including low placenta, partial and complete placenta previa.

Table 7. Association between IPI and other Perinatal Outcomes in Women with Emergency Cesarean Section. 


\begin{tabular}{|c|c|c|c|c|c|}
\hline & Index & $\begin{array}{l}\text { IPI of }<24 \\
\text { mon } \\
(n= \\
121)\end{array}$ & $\begin{array}{l}\text { IPI of } 60- \\
119 \text { mon } \\
(n=712)\end{array}$ & $\begin{array}{l}\text { IPI of } \geq \\
120 \text { mon } \\
(n=246)\end{array}$ & $\begin{array}{l}P \\
\text { value }\end{array}$ \\
\hline & & $\begin{array}{l}\text { aOR }(95 \% \\
\mathrm{Cl})\end{array}$ & $\begin{array}{l}\mathrm{aOR}(95 \% \\
\mathrm{Cl})\end{array}$ & $\begin{array}{l}\mathrm{aOR}(95 \% \\
\mathrm{Cl})\end{array}$ & \\
\hline Abnormal placental position & 0.160 & $\begin{array}{l}0.85(0.59- \\
1.22)\end{array}$ & $\begin{array}{l}1.17(0.82- \\
1.69)\end{array}$ & $\begin{array}{l}1.38(0.68- \\
2.86)\end{array}$ & 0.382 \\
\hline $\begin{array}{l}\text { Pernicious placenta with or without } \\
\text { placenta accreta }\end{array}$ & 0.057 & $\begin{array}{l}0.95(0.64- \\
1.38)\end{array}$ & $\begin{array}{l}1.06(0.72- \\
1.56)\end{array}$ & $\begin{array}{l}1.12(0.52- \\
2.43)\end{array}$ & 0.772 \\
\hline PROM & 0.068 & $\begin{array}{l}0.93(0.69- \\
1.25)\end{array}$ & $\begin{array}{l}1.07(0.8- \\
1.44)\end{array}$ & $\begin{array}{l}1.15(0.64- \\
2.08)\end{array}$ & 0.653 \\
\hline Uterine rupture & -0.157 & $\begin{array}{l}1.17(0.84- \\
1.63)\end{array}$ & $\begin{array}{l}0.86(0.61- \\
1.19)\end{array}$ & $\begin{array}{l}0.73(0.38- \\
1.42)\end{array}$ & 0.354 \\
\hline Postpartum hemorrhage & 0.195 & $\begin{array}{l}0.82(0.44- \\
1.49)\end{array}$ & $\begin{array}{l}1.21(0.67- \\
2.27)\end{array}$ & $\begin{array}{l}1.48(0.45- \\
5.14)\end{array}$ & 0.528 \\
\hline Hysterectomy & 0.192 & $\begin{array}{l}0.83(0.47- \\
1.42)\end{array}$ & $\begin{array}{l}1.21(0.71- \\
2.14)\end{array}$ & $\begin{array}{l}1.47(0.5- \\
4.56)\end{array}$ & 0.494 \\
\hline 1-min Apgar score $<10$ & -0.572 & $\begin{array}{l}1.77(0.47- \\
8.86)\end{array}$ & $\begin{array}{l}0.56(0.12- \\
2.14)\end{array}$ & $\begin{array}{l}0.32(0.01- \\
4.58)\end{array}$ & 0.426 \\
\hline NICU admission & 0.321 & $\begin{array}{l}0.73(0.49- \\
1.06)\end{array}$ & $\begin{array}{l}1.38(0.94- \\
2.04)\end{array}$ & $\begin{array}{l}1.90(0.89- \\
4.17)\end{array}$ & 0.102 \\
\hline
\end{tabular}

IPI, interpregnancy interval.

aOR, adjusted odds ratio; $\mathrm{Cl}$, confidential index; PROM, premature rupture of membrane.

Abnormal placental position, including low placenta, partial and complete placenta previa.

Adjusted for maternal age, maternal body mass index, education status, assisted reproductive technology, number of previous cesarean section, previous vaginal delivery.

\section{Figures}




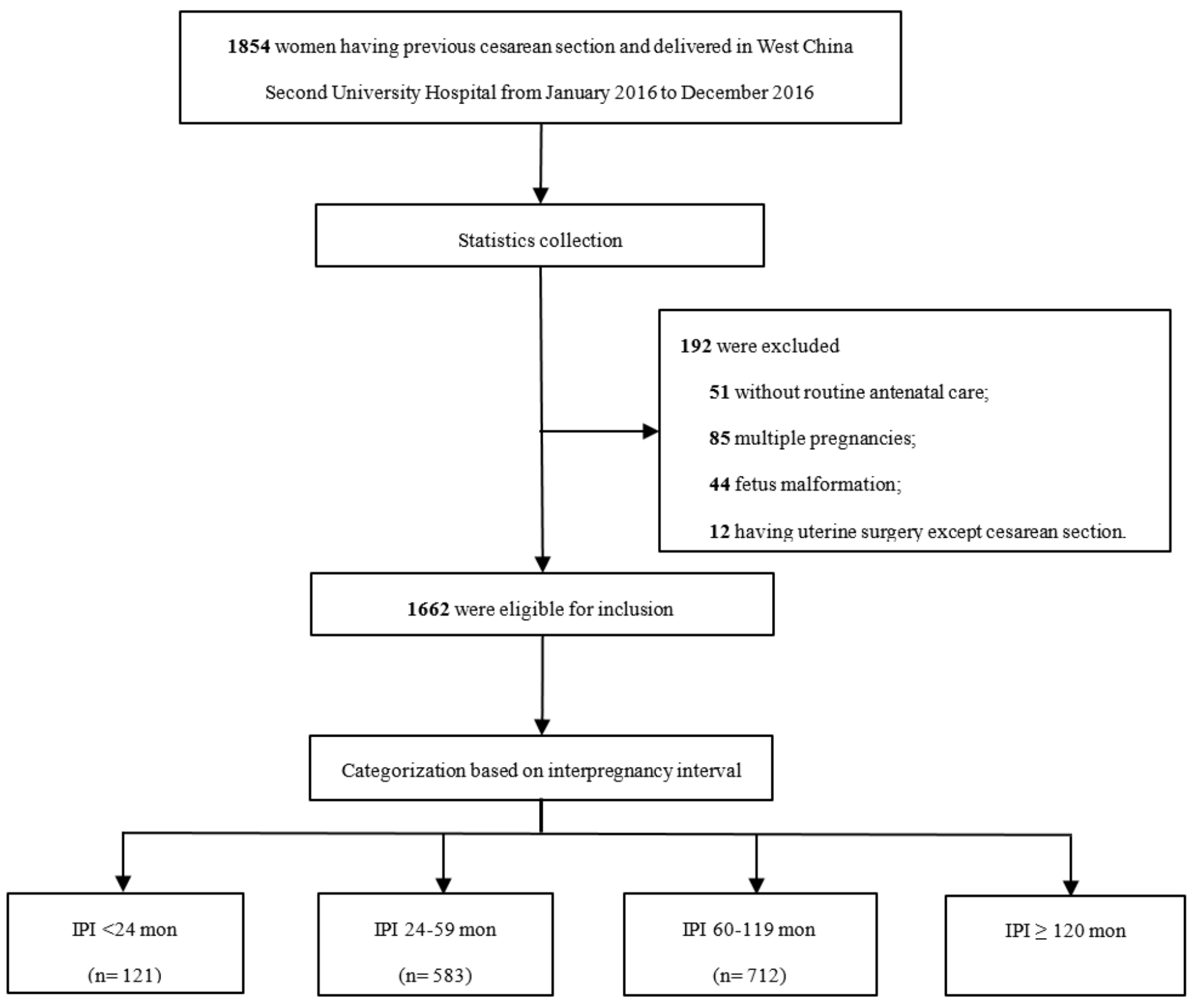

\section{Figure 1}

Flow chart of sample selection and statistics collection

\section{Supplementary Files}

This is a list of supplementary files associated with this preprint. Click to download.

- SupplementaryDocument.docx 